\title{
Tidal elevation, current, and energy flux in the area between the South China Sea and Java Sea
}

\author{
Zexun Wei ${ }^{1,2}$, Guohong Fang ${ }^{1,2}$, R. Dwi Susanto ${ }^{3}$, Tukul Rameyo Adi ${ }^{4}$, Bin Fan $^{1}$, Agus Setiawan ${ }^{4}$, Shujiang Li ${ }^{1}$, \\ Yonggang Wang ${ }^{1,2}$, and Xiumin Gao ${ }^{1}$ \\ ${ }^{1}$ The First Institute of Oceanography, State Oceanic Administration, Qingdao, China \\ ${ }^{2}$ Laboratory for Regional Oceanography and Numerical Modeling, Qingdao National Laboratory for Marine Science and \\ Technology, Qingdao, China \\ ${ }^{3}$ Department of Atmospheric and Oceanic Science, University of Maryland, College Park, Maryland, USA \\ ${ }^{4}$ Agency for Marine \& Fisheries Research and Development, Ministry of Marine Affairs and Fisheries, Jakarta, Indonesia
}

Correspondence to: Zexun Wei (weizx @ fio.org.cn)

Received: 10 October 2015 - Published in Ocean Sci. Discuss.: 20 November 2015

Revised: 21 March 2016 - Accepted: 21 March 2016 - Published: 8 April 2016

\begin{abstract}
The South China Sea (SCS) and the Java Sea (JS) are connected through the Karimata Strait, Gaspar Strait, and the southern Natuna Sea, where the tides are often used as open boundary condition for tidal simulation in the SCS or Indonesian seas. Tides, tidal currents, and tidal energy fluxes of the principle constituents $K_{1}, O_{1}, Q_{1}, M_{2}, S_{2}$, and $N_{2}$ at five stations in this area have been analyzed using in situ observational data. The results show that the diurnal tides are the dominant constituents in the entire study area. The constituent $K_{1}$ has the largest amplitude, exceeding $50 \mathrm{~cm}$, whereas the amplitudes of $M_{2}$ are smaller than $5 \mathrm{~cm}$ at all stations. The amplitudes of $S_{2}$ may exceed $M_{2}$ in the Karimata and Gaspar straits. Tidal currents are mostly of rectilinear type in this area. The semi-major axes lengths of the diurnal tidal current ellipses are about $10 \mathrm{~cm} \mathrm{~s}^{-1}$, and those of the semidiurnal tidal currents are smaller than $5 \mathrm{~cm} \mathrm{~s}^{-1}$. The diurnal tidal energy flows from the SCS to the JS. The semidiurnal tidal energy flows from the SCS to the JS through the Karimata Strait and the eastern part of the southern Natuna Sea but flows in the opposite direction in the Gaspar Strait and the western part of the southern Natuna Sea. Harmonic analysis of sea level and current observation also suggest that the study area is located in the antinodal band of the diurnal tidal waves, and in the nodal band of the semidiurnal tidal waves. Comparisons show that the existing models are basically consistent with the observational results, but further improvements are necessary.
\end{abstract}

\section{Introduction}

The tidal system in the Indonesian seas is the most complex one in the world, due to its rugged bottom topography, complicated coastline, and the interference of tidal waves propagating from the Pacific Ocean, Indian Ocean, and South China Sea (SCS). The earliest reports of tidal characteristics in the Indonesian seas can be traced back to the colonial period in the early twentieth century, which were recompiled by Wyrtki (1961) to construct diurnal and semidiurnal cotidal charts based on all available coastal and island observations. Although the results of Wyrtki (1961) are impressively reasonable in the Indonesian seas, mapping of the Indonesian tides are still incomplete owing to lack of observations. During the past decades, remarkable progress of investigations about tidal phenomena is benefited by use of satellite altimeter measurements and high-resolution numerical simulation, and with no exception in the Indonesian seas. Based on tide gauge observations and TOPEX/Poseidon (T/P) satellite altimeter data, Mazzega and Berge (1994) have produced the cotidal charts of $M_{2}$ and $K_{1}$ in the Indonesian seas using an inversion method. Using a barotropic tide model, Hatayama et al. (1996) investigated the characteristics of $M_{2}$ and $K_{1}$ tides and tidal currents in the Indonesian seas, which shows that the tidal currents in the Java Sea (JS) and in the vicinities of narrow straits, i.e., the Lombok and Malacca straits, are relatively strong.

Egbert and Erofeeva (2002) have assimilated satellite altimeter data into an inverse barotropic ocean tide model, pro- 
viding the cotidal charts and tidal currents for $M_{2}$ and $K_{1}$ constituents in the Indonesian seas. Their results are further reported by Ray et al. (2005), showing that there are three types of tides in the Indonesian seas: semidiurnal tides dominated but with significant diurnal inequality in the eastern Indonesian seas and the adjoining region of the Pacific Ocean; mixed diurnal tides in the region west of $118^{\circ} \mathrm{E}$; and diurnal tides west of the Kalimantan Island. Using the Regional Ocean Modeling System (ROMS), Robertson and Ffield $(2005,2008)$ have simulated the barotropic and baroclinic tides in the Indonesian seas for four tidal constituents $M_{2}, S_{2}, K_{1}$, and $O_{1}$. The results show that semidiurnal tides originate from both the Pacific and Indian oceans; whereas the diurnal tides are mainly from the Pacific Ocean. These results are confirmed by Teng et al. (2013), which suggests that the $M_{2}$ tide mainly propagates from the Indian Ocean into the Pacific Ocean through the eastern Indonesian seas, whereas the $K_{1}$ and $O_{1}$ tides propagate in an opposite direction. Although the characteristics of Indonesian tides have been simulated with more and more accurate geometry, and the results are indeed better than before, the tides in the southern SCS and JS, particularly in the junction region between the SCS and JS, are still not well determined as reflected by the fact that the simulated results are model dependent.

The junction area between the SCS and the JS, comprising the southern Natuna Sea, the Karimata Strait, and the Gaspar Strait, is a throat connecting the SCS and the Indonesian seas (Fig. 1). Furthermore, this area is also the convergent region of tidal waves that propagate from the SCS or the JS (Hatayama et al., 1996). It is worth noting that the simulated tidal currents in this area are discrepant among different models, even when the satellite altimeter data have been assimilated into the models. This is most possibly due to the coarse altimeter track separation (only one ascending track and one descending track pass through this region; Ray et al., 2005). Therefore, offshore observations are needed to provide a clearer recognition about the Indonesian tides and to assess the existing model results.

In this study, long-term water level and current profile observations at five stations (Fig. 1) are used to investigate the characteristics of tidal elevation, current, and energy flux between the SCS and JS. The results are not only important for understanding local dynamics but also useful for the determination of open boundary condition in tidal simulation of the SCS or Indonesian seas. The rest of the paper is organized as follows: Sect. 2 gives a description of the observed data; Sect. 3 presents the analyzed results of tides, tidal currents, and tidal energy fluxes; finally, a summary and discussion are given in Sect. 4.

\section{Data}

The data used in this study were obtained under the trilateral collaborative project "The South China Sea - Indone-

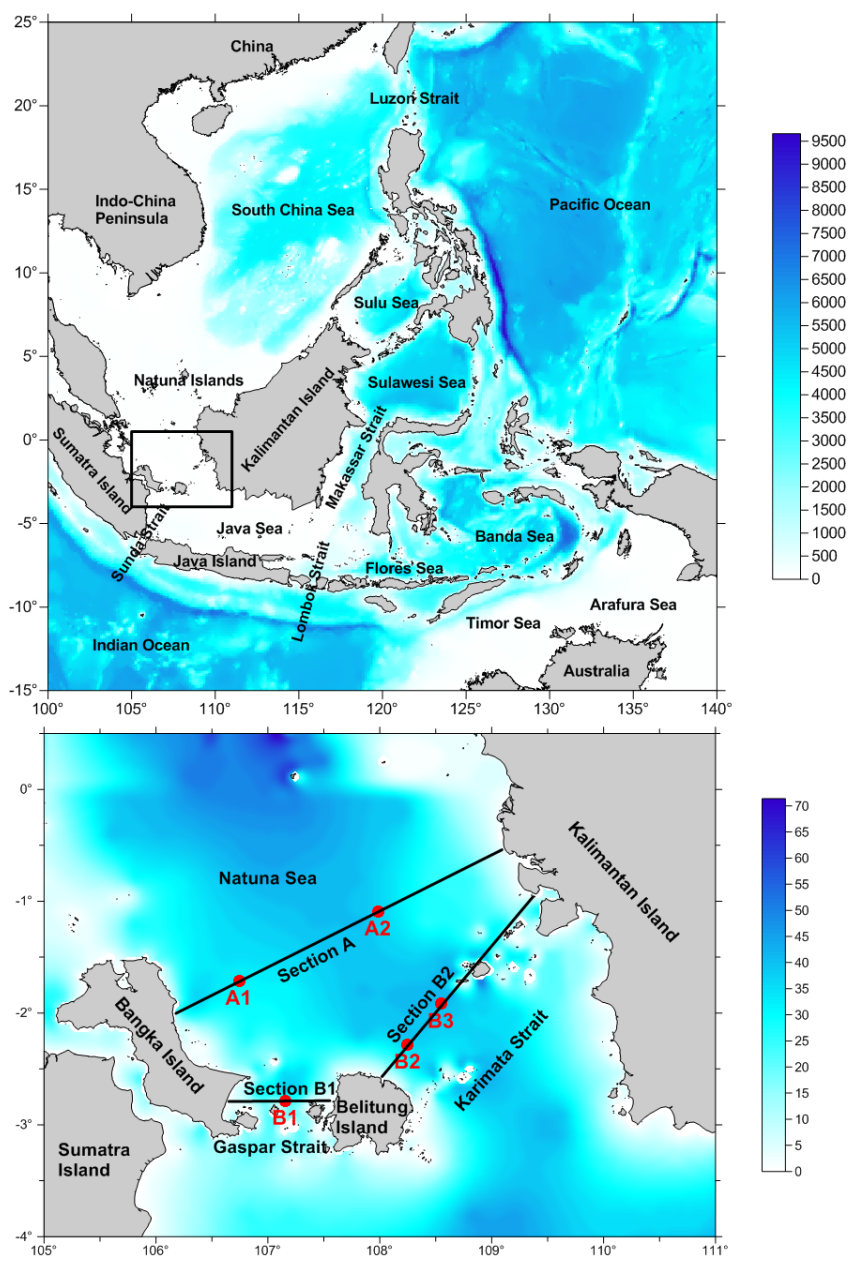

Figure 1. The map of the Indonesian seas (upper) and observational stations (lower). Isobaths are in meters.

sian seas Transport/Exchange (SITE) and Impacts on Seasonal Fish Migration" which was established in 2006 by the First Institute of Oceanography (FIO), State Oceanic Administration, China; the Agency for Marine and Fisheries Research and Development (AMFRD), Ministry of Marine Affairs and Fisheries, Indonesia; and the Lamont-Doherty Earth Observatory (LDEO), Columbia University, USA. The study area of the project was extended to the Sunda Strait in 2008, and the title of the collaborative program was changed to "The South China Sea - Indonesian seas Transport/Exchange (SITE) and Dynamics of Sunda and Lombok straits, and Their Impacts on Seasonal Fish Migration".

Current and sea level measurements were made from December 2007 to September 2011 in the southern Natuna Sea, Gaspar Strait and Karimata Strait by using trawl-resistant bottom mounts (TRBMs). The TRBMs were equipped with acoustic Doppler current profilers (ADCPs) and pressure gauges for measuring current profiles and sea levels. The volume, heat, and freshwater transports between the SCS and the Indonesian seas have been previously reported by Fang 
Table 1. Locations and water depths of the observational stations.

\begin{tabular}{ccccc}
\hline Station & Longitude & Latitude & $\begin{array}{c}\text { Depth } \\
(\mathrm{m})\end{array}$ & $\begin{array}{c}\text { Bin size } \\
(\mathrm{m})\end{array}$ \\
\hline $\mathrm{A} 1$ & $106^{\circ} 50.1^{\prime} \mathrm{E}$ & $1^{\circ} 40.0^{\prime} \mathrm{S}$ & 36.6 & 1 \\
$\mathrm{~A} 2$ & $107^{\circ} 59.2^{\prime} \mathrm{E}$ & $1^{\circ} 05.5^{\prime} \mathrm{S}$ & 48.0 & 2 \\
$\mathrm{~B} 1$ & $107^{\circ} 09.6^{\prime} \mathrm{E}$ & $2^{\circ} 46.8^{\prime} \mathrm{S}$ & 44.2 & 2 \\
$\mathrm{~B} 2$ & $108^{\circ} 15.0^{\prime} \mathrm{E}$ & $2^{\circ} 17.0^{\prime} \mathrm{S}$ & 42.8 & 2 \\
$\mathrm{~B} 3$ & $108^{\circ} 33.0^{\prime} \mathrm{E}$ & $1^{\circ} 54.9^{\prime} \mathrm{S}$ & 49.0 & 2 \\
\hline
\end{tabular}

Table 2. Record length of the obtained data.

\begin{tabular}{clcc}
\hline Station & $\begin{array}{l}\text { Measuring } \\
\text { parameter }\end{array}$ & $\begin{array}{c}\text { Starting and ending dates } \\
(\mathrm{yr} / \mathrm{mm} / \mathrm{dd})\end{array}$ & $\begin{array}{c}\text { Length } \\
(\mathrm{d})\end{array}$ \\
\hline A1 & $\begin{array}{l}\text { Current profile } \\
\text { Sea level }\end{array}$ & $\begin{array}{c}2008.01 .13-2008.02 .14 \\
2008.01 .13-2008.05 .05\end{array}$ & $\begin{array}{c}33 \\
114\end{array}$ \\
\hline A2 & Current profile & $\begin{array}{c}2007.12 .04-2008.01 .12 \\
2008.02 .15-2008.11 .01\end{array}$ & 301 \\
& Sea level & $2007.12 .02-2008.05 .05$ & 156 \\
\hline B1 & & $2008.05 .12-2008.10 .11$ & \\
& Current profile & $2008.11 .07-2008.11 .15$ & 168 \\
& & $2009.10 .19-2009.10 .24$ & \\
& Sea level & $2008.05 .12-2008.11 .03$ & 176 \\
\hline B2 & Current profile & $2008.11 .02-2010.11 .11$ & 740 \\
& Sea level & $2009.10 .18-2010.11 .11$ & 390 \\
\hline B3 & & $2008.11 .07-2009.10 .17$ & \\
& Current profile & $2009.10 .19-2010.11 .12$ & 960 \\
& & $2011.02 .17-2011.09 .29$ & \\
& Sea level & $2008.11 .06-2009.09 .09$ & 308 \\
\hline
\end{tabular}

et al. (2010) and Susanto et al. (2013). In the present paper we focus on the tides and tidal currents in the area as shown in the lower panel of Fig. 1. The measurements were conducted along three sections. Section A is located in the southern Natuna Sea between the Bangka Island and Kalimantan Island. Section B1 is in the Gaspar Strait between the Bangka Island and Belitung Island. Section B2 is located in the Karimata Strait between the Belitung Island and Kalimantan Island. The mean water depths of the five TRBM stations labeled A1, A2, B1, B2, and B3 are 36.6, 48.0, 44.2, 42.8 , and $49.0 \mathrm{~m}$, respectively (Table 1 ). The vertical bin size of ADCP measurements is $1 \mathrm{~m}$ for Station A1 and $2 \mathrm{~m}$ for other stations. The observational lengths of the sea level and current profile vary from 33 to 960 days as listed in Table 2.

\section{Analyzed results from observations}

\subsection{Tides}

Based on the observed sea level data, we extract the harmonic constants of six principle tidal constituents $K_{1}, O_{1}, Q_{1}, M_{2}$, $S_{2}$, and $N_{2}$ using the conventional harmonic analysis method developed by Wang and Fang (1981), which is nearly of the same performance as those developed by Foreman (1977) and Pawlowicz et al. (2002). Since the shortest record length is 33 days (current observation at Station A1), the Rayleigh criterion for separating these six constituents is satisfied. According to Rayleigh criterion, to separate $P_{1}$ from $K_{1}$ and $K_{2}$ from $S_{2}$ requires 182.6 days (e. g., Pugh, 1987, p. 113), thus the influences of $P_{1}$ on $K_{1}$ and $K_{2}$ on $S_{2}$ are corrected through introducing inference quantities (amplitude ratios and phase-lag differences between $P_{1}$ and $K_{1}$, and between $K_{2}$ and $S_{2}$ ) in this study. Moreover, a nearest tidal gauge station at Keppel Harbour $\left(103.82^{\circ} \mathrm{E}, 1.26^{\circ} \mathrm{N}\right)$ was used as an inference station, where the amplitude ratio and phase-lag difference of $P_{1}$ vs. $K_{1}$ are equal to 0.296 and $-10^{\circ}$, respectively, and those of $\mathrm{K}_{2}$ vs. $S_{2}$ are equal to 0.286 and $-2^{\circ}$, respectively.

The obtained amplitudes and Greenwich phase lags for the constituents $K_{1}, O_{1}, Q_{1}, M_{2}, S_{2}$, and $N_{2}$ at five stations are listed in Table 3. The harmonic constants of $P_{1}$ and $K_{2}$ can be derived from those of $K_{1}$ and $S_{2}$, respectively, listed in the table using the inference relations. It can be seen from the table that the constituent $K_{1}$ has the largest amplitude, exceeding $50 \mathrm{~cm}$. The second largest amplitude is that of constituent $O_{1}$, exceeding $30 \mathrm{~cm}$. For semidiurnal tides, the amplitudes are all smaller than $5 \mathrm{~cm}$ for $M_{2}$, while they are greater than $5 \mathrm{~cm}$ for $S_{2}$ at Stations B1, B2 and B3. For all of the five stations, it is found that the amplitudes of diurnal tides are much greater than those of semidiurnal tides, suggesting that diurnal tides are the dominant constituents in this area. Meanwhile, the results also show that the phase lags of the diurnal tides slightly increase from Section A to Sections B1 and B2. On the contrary, the phase lags of the semidiurnal tides dramatically increase from the eastern segment of Section A (represented by Station A2) to Section B2, and from Section B1 to the western segment of Section A (represented by Station A1). These results suggest that the study area is located in the antinodal band of the diurnal tidal waves but in the nodal band of the semidiurnal tidal waves. As a result, the amplitudes of diurnal tides are greater than those of semidiurnal tides, whereas the phase lags of diurnal tides change less than those of semidiurnal tides. The semidiurnal tidal waves in this area appear as a superposition of the incident waves propagating from the SCS and Indian Ocean (Ray et al., 2005; Teng et al., 2013). These two incident waves happen to have similar intensity and opposite phase, resulting in a nodal band. In contrast to the semidiurnal tides, the diurnal tidal waves in this area appear as a superposition of the incident waves propagating from the SCS and the Pacific Ocean (Ray et al., 2005; Teng et al., 2013). These two incident waves have basically the same phase, resulting in an antinodal band. 
Table 3. Tidal harmonic constants at the observation stations.

\begin{tabular}{lrr|rr|rr|rr|r|r|r}
\hline & \multicolumn{2}{c|}{$\mathrm{A} 1$} & \multicolumn{2}{|c|}{$\mathrm{A} 2$} & \multicolumn{2}{|c|}{ B1 } & \multicolumn{2}{|c|}{ B2 } & \multicolumn{2}{|c}{ B3 } \\
\cline { 2 - 10 } Constituent & $\begin{array}{r}H \\
(\mathrm{~cm})\end{array}$ & $\begin{array}{r}G \\
(\mathrm{deg})\end{array}$ & $\begin{array}{r}H \\
(\mathrm{~cm})\end{array}$ & $\begin{array}{r}G \\
(\mathrm{deg})\end{array}$ & $\begin{array}{r}H \\
(\mathrm{~cm})\end{array}$ & $\begin{array}{r}G \\
(\mathrm{deg})\end{array}$ & $\begin{array}{r}H \\
(\mathrm{~cm})\end{array}$ & $\begin{array}{r}G \\
(\mathrm{deg})\end{array}$ & $\begin{array}{r}H \\
(\mathrm{~cm})\end{array}$ & $\begin{array}{r}G \\
(\mathrm{deg})\end{array}$ \\
\hline$K_{1}$ & 59.1 & 30.0 & 50.8 & 27.0 & 59.6 & 33.3 & 54.4 & 45.4 & 57.2 & 36.2 \\
$O_{1}$ & 42.4 & 329.1 & 37.4 & 326.8 & 39.6 & 344.7 & 36.5 & 354.7 & 35.2 & 343.9 \\
$Q_{1}$ & 7.8 & 306.1 & 7.2 & 305.4 & 7.4 & 324.3 & 7.3 & 335.0 & 11.7 & 339.4 \\
$M_{2}$ & 3.8 & 341.3 & 4.4 & 322.9 & 4.3 & 236.4 & 1.9 & 117.5 & 2.2 & 68.5 \\
$S_{2}$ & 2.6 & 82.3 & 2.7 & 62.2 & 5.3 & 160.0 & 5.6 & 123.8 & 8.7 & 96.5 \\
$N_{2}$ & 0.4 & 306.6 & 0.8 & 284.9 & 2.0 & 206.6 & 0.6 & 192.6 & 0.5 & 8.7 \\
\hline
\end{tabular}

\subsection{Tidal currents}

The conventional harmonic method is applied to the current data analysis for extracting the harmonic constants of principle tidal constituents, as done in the analysis of tidal elevation in Sect. 3.1. The vertical structures of current ellipses of the constituents $K_{1}, O_{1}, Q_{1}, M_{2}, S_{2}$, and $N_{2}$ at each station are shown in Fig. 2. It can be seen that there are little vertical changes in the ellipses for all constituents at all stations, except for the top layer where the currents suffer strong disturbances due to winds, at some stations for some constituents. This vertical uniformity indicates that the tidal currents are basically of barotropic nature at all stations. Thus, we only use vertically averaged currents to reveal the characteristics of tidal currents in this study. Parameters of the vertically averaged current ellipse, including semi-major and -minor axes ( $W$ and $w$ ), ellipticity $(r)$, Greenwich phase-lag $(\phi)$, and direction $(\lambda)$ of the maximum current speed, are given in Table 4a-e. In the table, signs of the ellipticity represent the sense of the current vector rotation, positive for counterclockwise and negative for clockwise (the term of ellipticity generally refers to the flatness of an ellipse; here, it is defined as the ratio of the minor axis vs. major axis as done in Fang and Ichiye (1983) and Beardsley et al., 2004). We can see that at Station A1 the tidal currents rotate counterclockwise, except $N_{2}$. At Station A2 the tidal currents rotate counterclockwise, except $S_{2}$. At Station B1 the tidal currents rotate counterclockwise, except $M_{2}$ and $N_{2}$. At Station B2 the diurnal tidal currents rotate counterclockwise, the semidiurnal currents rotate clockwise. At Station B3 the diurnal tidal currents rotate counterclockwise, while the semidiurnal currents rotate clockwise except $N_{2}$. Figure 3 shows the current ellipses of $K_{1}, O_{1}, M_{2}$, and $S_{2}$. We can see that all stations show the characteristics of rectilinear tidal currents. The semi-major axes lengths of tidal current ellipses are $10 \mathrm{~cm} \mathrm{~s}^{-1}$ for diurnal constituents $K_{1}$ and $O_{1}$, with $O_{1}$ slightly smaller than $K_{1}$ in the most cases. At Station B1, however, which is located in the Gaspar Strait, diurnal tidal currents are significantly increased by the narrowing effect of the strait. In particular, the maximum speed of $O_{1}$ can approach $20 \mathrm{~cm} \mathrm{~s}^{-1}$. The semi-major axes lengths of tidal cur-

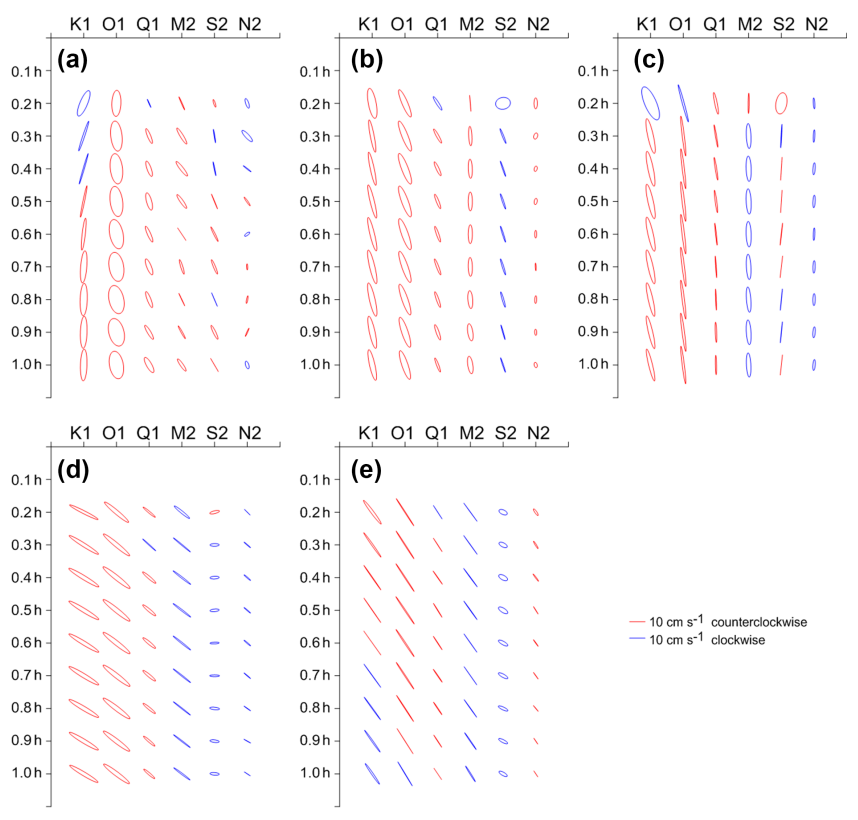

Figure 2. The vertical distributions of current ellipses of tides constituents $K_{1}, O_{1}, Q_{1}, M_{2}, S_{2}$, and $N_{2}$ at Stations A1 (a), A2 (b), B1 (c), B2 (d), and B3 (e).

rent ellipses of the semidiurnal constituents $M_{2}$ and $S_{2}$ are generally smaller than $5 \mathrm{~cm} \mathrm{~s}^{-1}$ at all stations.

\subsection{Tidal energy flux density}

The energy flux across a section of unit width is called flux density. For a specific constituent it can be calculated from harmonic constants of tidal elevation and tidal current by the following formula:

$$
\begin{aligned}
\left(F_{x}, F_{y}\right) & =\frac{\rho g h}{T} \int_{0}^{T} \zeta(u, v) \mathrm{d} t \\
& =\frac{1}{2} \rho g h H[U \cos (\xi-G), V \cos (\eta-G)],
\end{aligned}
$$

where $\left(F_{x}, F_{y}\right)$ are the east and north components of the tidal energy flux density, respectively, $T$ is the period of 

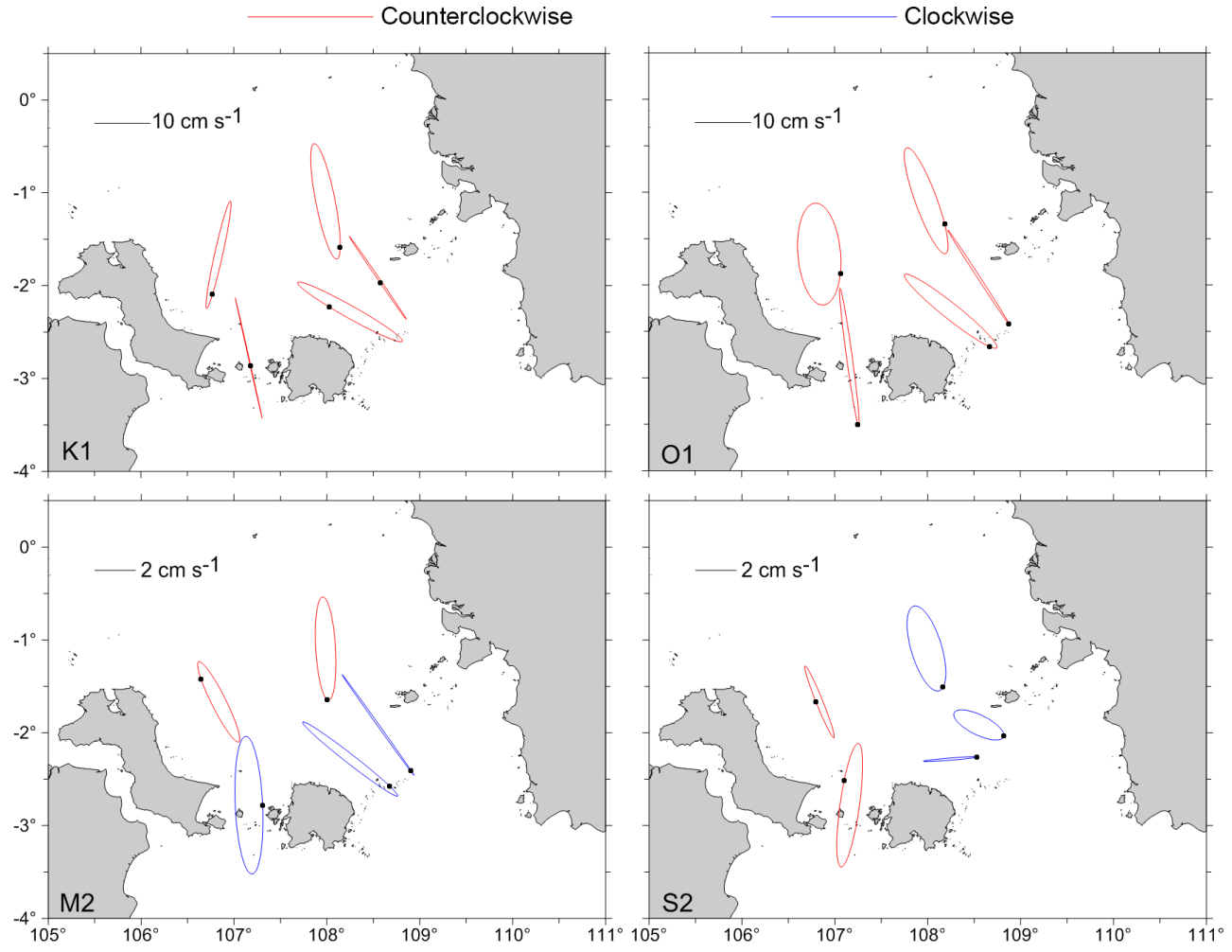

Figure 3. The vertically averaged tidal current ellipses of principle tidal constituents $K_{1}, O_{1}, M_{2}$, and $S_{2}$ at the observational stations. Dots on the ellipses represent the tips of the tidal current vectors at 00:00 GMT.

the tidal constituent, $\rho$ is the water density (taken to be $1021 \mathrm{~kg} \mathrm{~m}^{-3}$ for a temperature of $28^{\circ} \mathrm{C}$ and a salinity of 33 which are roughly equal to the mean temperature and salinity in the study area), $g$ is the gravity acceleration, $h$ is the undisturbed water depth, $\zeta$ is the tidal elevation, $(u, v)$ are the east and north components of vertically averaged tidal currents, $t$ is the time, $H$ and $G$ are the amplitude and phase lag of the tide, $(U, V)$ are the amplitudes of the east and north components of vertically averaged tidal current, and $(\xi, \eta)$ are the phase lags of the corresponding components of tidal current.

Table 5 lists the east component of energy flux density $F_{x}$, north component of energy flux density $F_{y}$, magnitude $F$, and direction $\theta$ (in degrees measured clockwise from the true north) at Stations A1, A2, B1, B2, and B3 from observed harmonic constants. Moreover, the direction differences between the current major axis and the energy flux vector $\Delta \theta$ are also given in Table 5 (since the current ellipse has two semi-major axes with opposite directions, in the calculation of $\Delta \theta$ we choose the one that is aligned with the energy flux). Figure 4 shows the tidal energy flux densities of the principal diurnal tidal constituents $K_{1}$ and $O_{1}$ and the principal semidiurnal tidal constituents $M_{2}$ and $S_{2}$.

From Table 5 and Fig. 4, it is found that for diurnal tides, the tidal energy flows from the SCS to the JS at all stations. Maximum energy flux densities of 11.6 (for $K_{1}$ ) and 14.7 (for $O_{1}$ ) $\mathrm{kW} \mathrm{m}^{-1}$ appear at Station B1 in the Gaspar
Strait. On the other hand, the tidal energy flux for $M_{2}$ tide is quite small and flows to the JS only in the eastern passage of the study area, including the Karimata Strait. In the western passage, including the Gaspar Strait, the $M_{2}$ tidal energy flows oppositely from the JS to the SCS. However, for $S_{2}$ tide, the tidal energy flux flows from SCS to JS at all stations except B2. In the Indonesian seas, the magnitudes of tidal energy densities may exceed $100 \mathrm{~kW} \mathrm{~m}^{-1}$ (Ray et al., 2005; Teng et al., 2013), thus the energy fluxes in the study area are relatively small. Table 5 shows that direction differences between energy flux and current major axis are generally small. From directions of energy fluxes shown in Fig. 4 we can judge that (1) the southward incident diurnal and $S_{2}$ waves from the SCS are slightly stronger than the northward incident diurnal and $S_{2}$ waves from the JS and (2) the southward incident $M_{2}$ wave from the SCS is slightly stronger than the northward incident $M_{2}$ wave from the JS in the eastern passage, and is slightly weaker than the latter in the western passage. The feature (2) further indicates that the $M_{2}$ amphidromic point should be located between the A1 and B1 line and the $\mathrm{A} 2$ and $\mathrm{B} 2$ line, and the amphidromic system should rotate clockwise. 
Table 4. Vertically averaged tidal current ellipse.

\begin{tabular}{lrrrrr}
\hline Constituent & $\begin{array}{r}W \\
\left(\mathrm{~cm} \mathrm{~s}^{-1}\right)\end{array}$ & $\begin{array}{r}w \\
\left(\mathrm{~cm} \mathrm{~s}^{-1}\right)\end{array}$ & & $\begin{array}{r}\phi \\
(\mathrm{deg})\end{array}$ & $\begin{array}{r}\lambda \\
(\mathrm{deg})\end{array}$ \\
\hline (a) Station A1 & & & & & \\
\hline$K_{1}$ & 9.63 & 0.70 & 0.07 & $136.6 / 316.6$ & $12.6 / 192.6$ \\
$O_{1}$ & 8.02 & 3.34 & 0.42 & $114.2 / 294.2$ & $355.2 / 175.2$ \\
$Q_{1}$ & 2.25 & 0.58 & 0.26 & $108.0 / 288.0$ & $338.0 / 158.0$ \\
$M_{2}$ & 2.34 & 0.38 & 0.16 & $128.9 / 308.9$ & $153.4 / 333.4$ \\
$S_{2}$ & 1.83 & 0.16 & 0.09 & $92.1 / 272.1$ & $158.1 / 338.0$ \\
$N_{2}$ & 0.97 & 0.19 & -0.19 & $113.3 / 293.3$ & $158.1 / 338.1$
\end{tabular}

(b) Station A2

\begin{tabular}{lrrrrr}
\hline$K_{1}$ & 11.51 & 1.89 & 0.16 & $144.9 / 324.9$ & $348.8 / 168.8$ \\
$O_{1}$ & 10.31 & 1.97 & 0.19 & $120.3 / 300.3$ & $339.9 / 159.9$ \\
$Q_{1}$ & 2.41 & 0.16 & 0.06 & $103.4 / 283.4$ & $335.8 / 155.8$ \\
$M_{2}$ & 3.00 & 0.58 & 0.19 & $8.7 / 188.7$ & $176.7 / 356.7$ \\
$S_{2}$ & 2.28 & 0.79 & -0.35 & $18.5 / 198.5$ & $163.3 / 343.3$ \\
$N_{2}$ & 0.80 & 0.30 & 0.37 & $164.3 / 344.3$ & $0.2 / 180.2$ \\
\hline
\end{tabular}

\begin{tabular}{lrrrrr}
\hline (c) Station B1 & & & & & \\
\hline$K_{1}$ & 13.32 & 0.05 & 0.00 & $82.4 / 262.5$ & $167.4 / 347.4$ \\
$O_{1}$ & 19.08 & 0.77 & 0.04 & $13.5 / 193.5$ & $172.2 / 352.2$ \\
$Q_{1}$ & 4.32 & 0.39 & 0.09 & $162.9 / 342.9$ & $354.0 / 174.0$ \\
$M_{2}$ & 5.41 & 1.07 & -0.20 & $89.0 / 269.0$ & $177.4 / 357.4$ \\
$S_{2}$ & 4.34 & 0.67 & 0.16 & $112.6 / 292.5$ & $188.0 / 8.0$ \\
$N_{2}$ & 1.40 & 0.30 & -0.21 & $89.1 / 269.1$ & $180.7 / 0.7$
\end{tabular}

(d) Station B2

\begin{tabular}{lrrrrr}
\hline$K_{1}$ & 12.25 & 1.27 & 0.10 & $109.7 / 289.7$ & $119.3 / 299.3$ \\
$O_{1}$ & 11.56 & 1.55 & 0.13 & $25.9 / 205.9$ & $128.5 / 308.5$ \\
$Q_{1}$ & 2.32 & 0.36 & 0.16 & $169.4 / 349.4$ & $309.5 / 129.5$ \\
$M_{2}$ & 4.05 & 0.31 & -0.08 & $37.8 / 217.8$ & $127.9 / 307.9$ \\
$S_{2}$ & 1.10 & 0.04 & -0.04 & $157.4 / 337.4$ & $265.3 / 85.3$ \\
$N_{2}$ & 0.86 & 0.05 & -0.05 & $5.0 / 185.0$ & $125.5 / 305.5$
\end{tabular}

\begin{tabular}{lrrrrr}
\hline (e) Station B3 & & & & & \\
\hline$K_{1}$ & 7.77 & 0.15 & 0.02 & $84.0 / 264.0$ & $145.5 / 325.5$ \\
$O_{1}$ & 10.26 & 0.24 & 0.02 & $4.8 / 184.8$ & $146.9 / 326.9$ \\
$Q_{1}$ & 2.25 & 0.04 & 0.02 & $146.4 / 326.4$ & $327.7 / 147.7$ \\
$M_{2}$ & 4.30 & 0.06 & -0.01 & $25.1 / 205.1$ & $144.5 / 324.5$ \\
$S_{2}$ & 1.10 & 0.40 & -0.36 & $7.8 / 187.8$ & $116.1 / 296.1$ \\
$N_{2}$ & 0.86 & 0.08 & 0.10 & $178.6 / 358.6$ & $324.6 / 144.6$ \\
\hline
\end{tabular}

$W$ - length of the semi-major axis (i.e., maximum speed); $w$ - length of the semi-minor axis (i.e., minimum speed); $r$ - ellipticity, equal to the ratio $w / W$ with signs representing the direction of the current vector rotation (positive/negative for counterclockwise/clockwise); $\phi$ - Greenwich phase lag of the maximum current speed; $\lambda$-direction of the semi-major axis measured clockwise from north. Both $\phi$ and $\lambda$ have two values with a difference of $180^{\circ}$, respectively.

\subsection{Tidal elevation gradients}

Based on the tidal currents, the gradients of sea surface height can be derived from the shallow water equations, as done by Proudman and Doodson (1924). The equations in the $x$ (positive for eastward) and $y$ (positive for northward) directions are respectively:

$\frac{\partial u}{\partial t}=f v-g(a-\bar{a})-p$

$\frac{\partial v}{\partial t}=-f u-g(b-\bar{b})-q$,

where $f$ is the Coriolis parameter, and $a=\frac{\partial \zeta}{\partial x}, \bar{a}=\frac{\partial \bar{\zeta}}{\partial x}, b=$ $\frac{\partial \zeta}{\partial y}, \bar{b}=\frac{\partial \bar{\zeta}}{\partial y}$ are elevation gradients of tides and equilibrium 

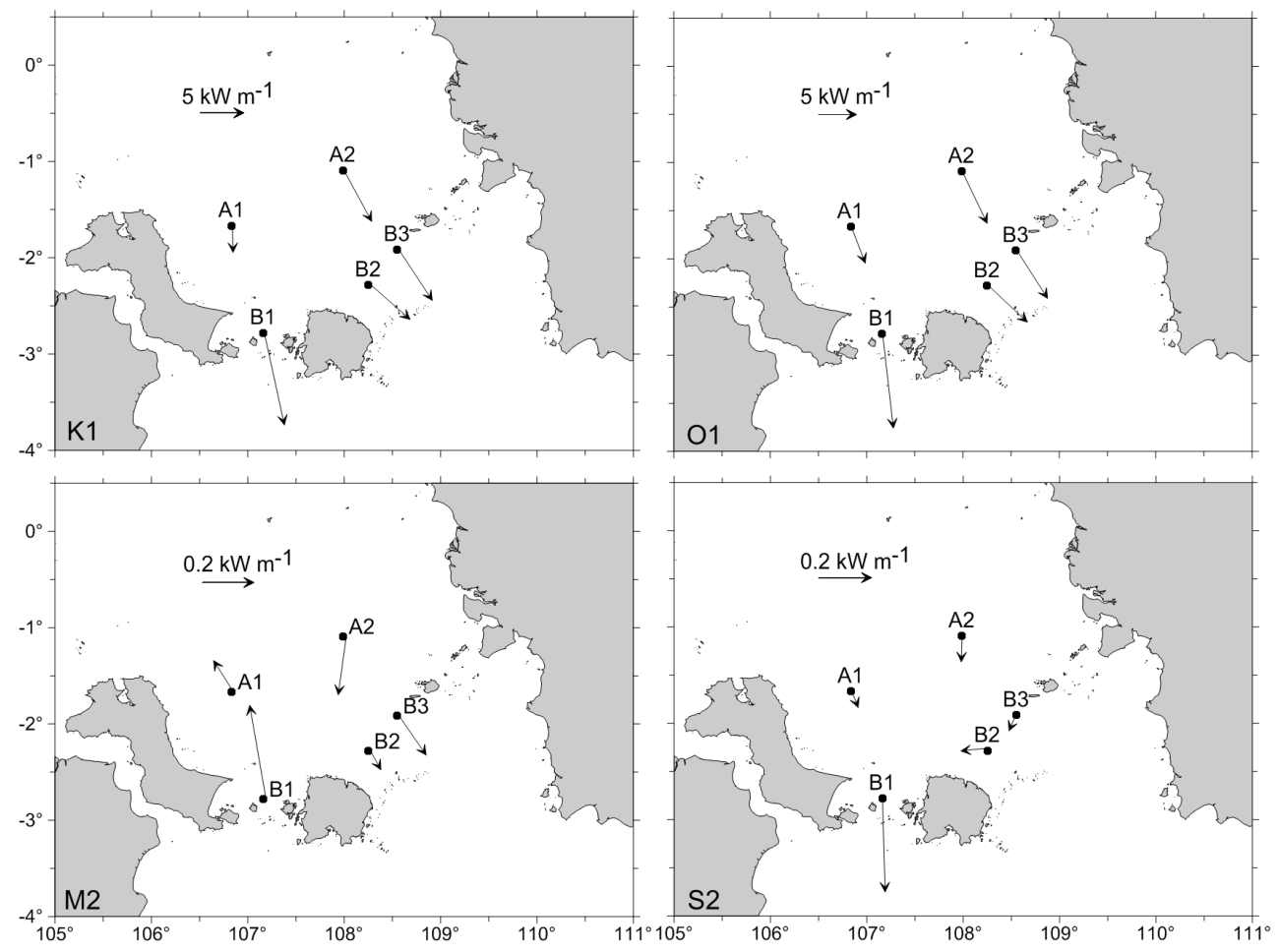

Figure 4. Horizontal tidal energy flux density.

tides, respectively. The vector of $(a, b)$ is called the tidal elevation gradient vector. The equilibrium tide $\bar{\zeta}$ has been adjusted for the earth's elastic response, and is equal to (see e.g., Fang et al., 1999)

$\left\{\begin{array}{c}\bar{\zeta}=C \sin 2 \phi \cos (\omega t+\lambda) \text { for diurnal tides } \\ \left(C_{K_{1}}=0.104 \mathrm{~m}, C_{\mathrm{O}_{1}}=0.070 \mathrm{~m}\right) \\ \bar{\zeta}=C \cos ^{2} \phi \cos (\omega t+2 \lambda) \text { for semidiurnal tides } \\ \left(C_{\mathrm{M}_{2}}=0.168 \mathrm{~m}, C_{S_{2}}=0.078 \mathrm{~m}\right),\end{array}\right.$

where $\lambda$ and $\phi$ are longitude and latitude, respectively. In the Eqs. (2) and (3), $p$ and $q$ represent the east and north components of bottom friction:

$p=\frac{1}{h} C_{D}\left(u^{2}+v^{2}\right)^{1 / 2} u$

$q=\frac{1}{h} C_{D}\left(u^{2}+v^{2}\right)^{1 / 2} v$,

where $C_{D}$ is the drag coefficient and is taken to be 0.0025 in this study. The values of $p$ and $q$ can be obtained by inserting the observed values of $u$ and $v$ into Eqs. (5) and (6), respectively, and can be decomposed into various constituents with frequencies equal to corresponding tidal constituents through harmonic analysis (similar to the analysis of $u$ and $v$ ). The amplitudes and phase lags of the obtained constituents of $p$ $(q)$ are denoted as $P$ and $\mu(Q$ and $\nu)$, respectively.
For a given constituent with angular speed equal to $\omega$, we have

$$
\left\{\begin{array}{l}
u=U \cos (\omega t-\xi)=U^{\prime} \cos \omega t+U^{\prime \prime} \sin \omega t \\
v=V \cos (\omega t-\eta)=V^{\prime} \cos \omega t+V^{\prime \prime} \sin \omega t \\
\zeta=H \cos (\omega t-G)=H^{\prime} \cos \omega t+H^{\prime \prime} \sin \omega t \\
\bar{\zeta}=\bar{H} \cos (\omega t-\bar{G})=\overline{H^{\prime}} \cos \omega t+\overline{H^{\prime \prime}} \sin \omega t \\
p=P \cos (\omega t-\mu)=P^{\prime} \cos \omega t+P^{\prime \prime} \sin \omega t \\
q=Q \cos (\omega t-v)=Q^{\prime} \cos \omega t+Q^{\prime \prime} \sin \omega t,
\end{array}\right.
$$

where $U^{\prime}=U \cos \xi, U^{\prime \prime}=U \sin \xi$ (the rest are similar). Inserting Eq. (7) into Eqs. (2) and (3) yields

$$
\left\{\begin{array}{l}
A^{\prime}=\bar{A}^{\prime}+\left(-\omega U^{\prime \prime}+f V^{\prime}-P^{\prime}\right) / g \\
A^{\prime \prime}=\bar{A}^{\prime \prime}+\left(\omega U^{\prime}+f V^{\prime \prime}-P^{\prime \prime}\right) / g
\end{array}\right.
$$

and

$\left\{\begin{array}{l}B^{\prime}=\bar{B}^{\prime}+\left(-\omega V^{\prime \prime}-f U^{\prime}-Q^{\prime}\right) / g \\ B^{\prime \prime}=\bar{B}^{\prime \prime}+\left(\omega V^{\prime}-f U^{\prime \prime}-Q^{\prime \prime}\right) / g,\end{array}\right.$

where $\quad\left(A^{\prime}, A^{\prime \prime}, \bar{A}^{\prime}, \bar{A}^{\prime \prime}\right)=\frac{\partial}{\partial x}\left(H^{\prime}, H^{\prime \prime}, \bar{H}^{\prime}, \bar{H}^{\prime \prime}\right), \quad$ and $\left(B^{\prime}, B^{\prime \prime}, \bar{B}^{\prime}, \bar{B}^{\prime \prime}\right)=\frac{\partial}{\partial y}\left(H^{\prime}, H^{\prime \prime}, \bar{H}^{\prime}, \bar{H}^{\prime \prime}\right)$. The elevation gradients of equilibrium tides $\left(\bar{A}^{\prime}, \bar{A}^{\prime \prime}, \bar{B}^{\prime}, \bar{B}^{\prime \prime}\right)$ can be obtained from Eq. (4). By inserting $\left(\bar{A}^{\prime}, \bar{A}^{\prime \prime}, \bar{B}^{\prime}, \bar{B}^{\prime \prime}\right)$ into Eqs. (8) and (9), we can get the values of the tidal elevation gradients $\left(A^{\prime}, A^{\prime \prime} ; B^{\prime}, B^{\prime \prime}\right)$. The tidal elevation 
Table 5. Tidal energy flux density.

\begin{tabular}{|c|c|c|c|c|c|}
\hline Constituent & $\begin{array}{r}F_{X} \\
\left(\mathrm{~kW} \mathrm{~m}^{-1}\right)\end{array}$ & $\begin{array}{r}F_{y} \\
\left(\mathrm{~kW} \mathrm{~m}^{-1}\right)\end{array}$ & $\begin{array}{r}F \\
\left(\mathrm{~kW} \mathrm{~m}^{-1}\right)\end{array}$ & $\begin{array}{r}\theta \\
(\operatorname{deg})\end{array}$ & $\begin{array}{r}\Delta \theta \\
(\operatorname{deg})\end{array}$ \\
\hline \multicolumn{6}{|c|}{ (a) Station A1 } \\
\hline$K_{1}$ & 0.0628 & -3.0800 & 3.0806 & 178.8 & -13.8 \\
\hline$O_{1}$ & 1.9216 & -5.0011 & 5.3576 & 159.0 & -16.2 \\
\hline$Q_{1}$ & 0.1394 & -0.2759 & 0.3091 & 153.2 & -4.8 \\
\hline$M_{2}$ & -0.0746 & 0.1175 & 0.1392 & 327.6 & -5.8 \\
\hline$S_{2}$ & 0.0312 & -0.0807 & 0.0865 & 158.9 & 0.8 \\
\hline $\mathrm{N}_{2}$ & -0.0023 & 0.0066 & 0.0069 & 340.7 & 2.6 \\
\hline \multicolumn{6}{|c|}{ (b) Station A2 } \\
\hline$K_{1}$ & 3.2910 & -6.0846 & 6.9176 & 151.6 & -17.2 \\
\hline$O_{1}$ & 3.6167 & -7.5581 & 8.3789 & 154.4 & -5.5 \\
\hline$Q_{1}$ & 0.1690 & -0.3507 & 0.3893 & 154.3 & -1.5 \\
\hline$M_{2}$ & -0.0310 & -0.2249 & 0.2270 & 187.9 & 11.2 \\
\hline$S_{2}$ & -0.0032 & -0.1135 & 0.1135 & 181.6 & 18.3 \\
\hline$N_{2}$ & -0.0050 & -0.0079 & 0.0093 & 212.6 & 32.4 \\
\hline \multicolumn{6}{|c|}{ (c) Station B1 } \\
\hline$K_{1}$ & 2.4623 & -11.2900 & 11.5554 & 167.7 & 0.3 \\
\hline$O_{1}$ & 1.6738 & -14.6383 & 14.7337 & 173.5 & 1.3 \\
\hline$Q_{1}$ & 0.0506 & -0.6735 & 0.6754 & 175.7 & 1.7 \\
\hline$M_{2}$ & -0.0752 & 0.4329 & 0.4394 & 350.1 & -7.3 \\
\hline$S_{2}$ & 0.0098 & -0.3511 & 0.3512 & 178.4 & -9.6 \\
\hline $\mathrm{N}_{2}$ & -0.0115 & 0.0289 & 0.0311 & 338.3 & -22.4 \\
\hline \multicolumn{6}{|c|}{ (d) Station B2 } \\
\hline$K_{1}$ & 4.7790 & -4.2226 & 6.3772 & 131.5 & 12.2 \\
\hline$O_{1}$ & 5.6926 & -5.3376 & 7.8035 & 133.2 & 4.7 \\
\hline$Q_{1}$ & 0.2630 & -0.2354 & 0.3530 & 131.8 & 2.3 \\
\hline$M_{2}$ & 0.0157 & -0.0282 & 0.0323 & 150.8 & 22.9 \\
\hline$S_{2}$ & -0.1103 & -0.0120 & 0.1109 & 263.8 & -1.5 \\
\hline $\mathrm{N}_{2}$ & -0.0089 & 0.0065 & 0.0110 & 305.9 & 0.4 \\
\hline \multicolumn{6}{|c|}{ (e) Station B3 } \\
\hline$K_{1}$ & 4.0403 & -6.1473 & 7.3562 & 146.7 & 1.2 \\
\hline$O_{1}$ & 4.4794 & -7.0172 & 8.3251 & 147.4 & 0.5 \\
\hline$Q_{1}$ & 0.3395 & -0.5330 & 0.6319 & 147.5 & -0.2 \\
\hline$M_{2}$ & 0.0966 & -0.1394 & 0.1696 & 145.3 & 0.8 \\
\hline$S_{2}$ & -0.0328 & -0.0787 & 0.0853 & 202.6 & 86.5 \\
\hline $\mathrm{N}_{2}$ & 0.0062 & -0.0084 & 0.0104 & 143.7 & -0.9 \\
\hline
\end{tabular}

gradient ellipse parameters can be obtained from the values of $\left(A^{\prime}, A^{\prime \prime} ; B^{\prime}, B^{\prime \prime}\right)$ in the same way as the calculation of tidal current ellipse parameters from the values of $\left(U^{\prime}, U^{\prime \prime}, V^{\prime}, V^{\prime \prime}\right)$. The tidal elevation gradient ellipse has a close relationship to the tidal regime, that is, the distribution of co-amplitude and co-phase-lag contours (see Appendix B for detailed derivation). In particular, if the tidal elevation gradient ellipse rotates counterclockwise (clockwise) the angle from the vector $\operatorname{grad} H$ to the vector $\operatorname{grad} G$ on the cotidal chart lies between 0 and $180^{\circ}\left(0\right.$ and $\left.-180^{\circ}\right)$.

Figure 5 shows the tidal elevation gradient ellipses of $K_{1}$, $O_{1}, M_{2}$ and $S_{2}$ at the observation stations. For $K_{1}$ and $O_{1}$ tides, the tidal elevation gradient vectors rotate counterclockwise at Stations A1, A2, and B2, and rotate clockwise at Stations B1 and B3. For $M_{2}$ tide, the tidal elevation gradient vectors rotate counterclockwise at Stations A1 and A2, and 

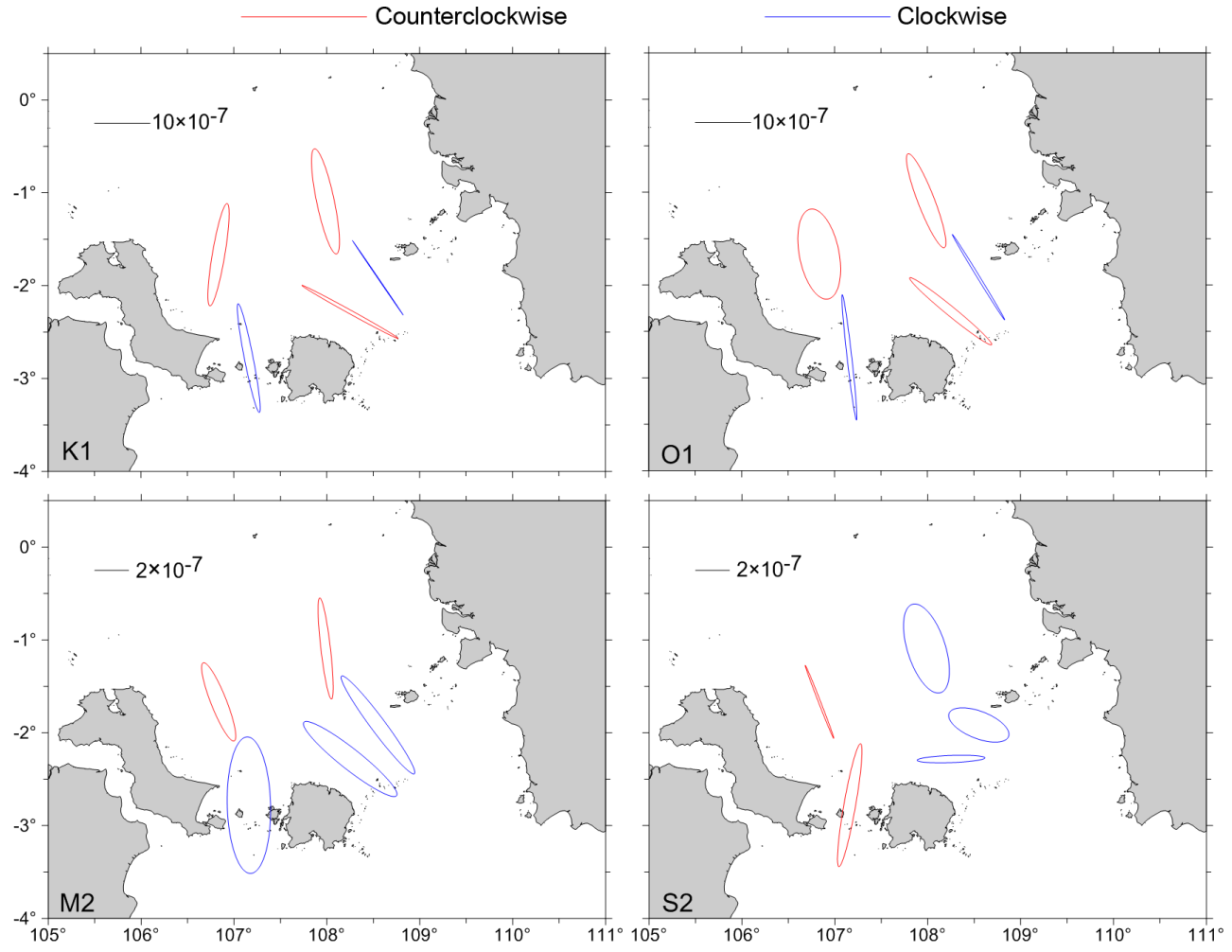

Figure 5. The tidal elevation gradient ellipses of $K_{1}, O_{1}, M_{2}$, and $S_{2}$ at the observational stations.

rotate clockwise at Stations B1, B2, and B3. However, for $S_{2}$ tide, the tidal elevation gradient vectors rotate counterclockwise at Stations A1 and B1, and rotate clockwise at Stations $\mathrm{A} 2$, B2, and B3.

From the known tidal elevation gradient we have calculated the directions of the co-tidal and co-amplitude lines as done by Proudman and Doodson (1924) in constructing cotidal charts of the North Sea. Since the purpose of the present work is not to construct co-tidal charts in the study area, the obtained results are not shown here.

\section{Summary and discussion}

The sea level and current data obtained at five stations along three sections between the SCS and JS are analyzed to reveal the characteristics of tides and tidal currents in this region. The results show that the ratios of diurnal vs. semidiurnal tides amplitudes $\left(H_{O_{1}}+H_{K_{1}}\right) /\left(H_{M_{2}}+H_{S_{2}}\right)$ are greater than 8 at all stations, suggesting predominance of the diurnal tides in the study area. The amplitudes of $K_{1}$ are larger than $50 \mathrm{~cm}$ at all stations with the phase lags being around $30^{\circ}$. In comparison, the amplitudes of $M_{2}$ are smaller than $5 \mathrm{~cm}$. It is worth mentioning that the amplitudes of $S_{2}$ may exceed $M_{2}$ in the Karimata and Gaspar straits. The greater amplitudes and smaller spatial phase-lag changes of diurnal tides compared with those of semidiurnal tides indicate that the study area is located in the antinodal band of the diurnal tidal waves but in the nodal band of the semidiurnal tidal waves.

The tidal currents are analyzed based on the ADCP observations on board of five TRBMs, showing that the tidal currents are of rectilinear type at all stations. The semi-major axes lengths of tidal current ellipses are about $10 \mathrm{~cm} \mathrm{~s}^{-1}$ for diurnal tides, with $O_{1}$ slightly smaller than $K_{1}$ in the most cases. However, in the Gaspar Strait, $O_{1}$ may exceed $K_{1}$ and approaches to $20 \mathrm{~cm} \mathrm{~s}^{-1}$ at Station B1. The maximum speeds of semidiurnal constituents $M_{2}$ and $S_{2}$ are generally smaller than $5 \mathrm{~cm} \mathrm{~s}^{-1}$ at all stations.

By examining the tidal energy fluxes at each station, we found that the diurnal tidal energy flows from the SCS to the JS with the maximum energy flux density of $14.7 \mathrm{~kW} \mathrm{~m}^{-1}$ appearing at Station B1. The tidal energy flux distributions of semidiurnal tides are quite complicated; $M_{2}$ energy flux flows southward in the Karimata Strait but northward in the Gaspar Strait and $S_{2}$ energy flux generally flows from the SCS to JS except at Station B2.

With these long-term observational results, we can make an accuracy assessment on the existing tidal models for the study area. Four representative tidal models, TPXO7.2 (Egbert and Erofeeva, 2002; $0.25^{\circ} \times 0.25^{\circ}$ resolution), GOT00.2 (Ray, 1999; $0.5^{\circ} \times 0.5^{\circ}$ ), NAO.99b (Matsumoto et al., 2000; $0.5^{\circ} \times 0.5^{\circ}$ ), and DTU10 (Cheng and Andersen, 2011; $0.125^{\circ} \times 0.125^{\circ}$ ), are compared with our observations for tides (see Appendix A). The comparison shows that the am- 
plitudes and phase lags of the model results are generally consistent with the observations. However, discrepancies of the model results from the observations are not ignorable. DTU10 is the best one in the area between the South China Sea and Java Sea, due to use of more satellites and longer altimeter measurements. Moreover, DTU10 has the highest resolution among these four tide models. It indicates that if the open boundary of a tidal model is located in the area between the South China Sea and Java Sea, DTU10 is the best choice for deriving open boundary condition. The tidal currents of the model TPXO7.2 are also compared with observations in Appendix A (the models GOT00.2, NAO.99b, and DTU10 do not contain tidal currents). The comparison shows that the relative discrepancies are generally greater than those for tidal elevations. Therefore, further effort of assimilating the in situ observations into numerical models in the future is worthwhile in providing more accurate knowledge of the tidal systems in the study area. Since the study area is often chosen as an open boundary in simulating tides in the SCS or Indonesian seas (e. g., Fang et al., 1999; Gao et al., 2015) the observational results of this study are expected to be useful in improving model results. 


\section{Appendix A: Comparison with existing model results}

Table A1 shows the comparison of the tidal harmonic constants between observations and the global ocean tide models TPXO7.2, GOT00.2, NAO.99b, and DTU10. Figure A1 shows the co-tidal charts for $K_{1}, O_{1}, M_{2}$, and $S_{2}$ based on DTU10. For $K_{1}$, the tidal waves from the SCS and the JS meet in the study area. For $O_{1}$, the tidal wave propagates from the SCS to the JS. For $M_{2}$, the tidal wave propagates clockwise around the Belitung Island. For $S_{2}$, the tidal wave also propagates clockwise around the Belitung Island, and a clockwise amphidromic system exist near Station A1. $K_{1}$ has the largest amplitude (exceeding $0.6 \mathrm{~m}$ near the Bangka Island), and the next is $O_{1}$; the amplitudes of $M_{2}$ and $S_{2}$ are significantly smaller.

Table A2 shows the comparison of the tidal current harmonic constants between observations and TPXO7.2. The Cressman interpolation method (Cressman, 1959) is used here.
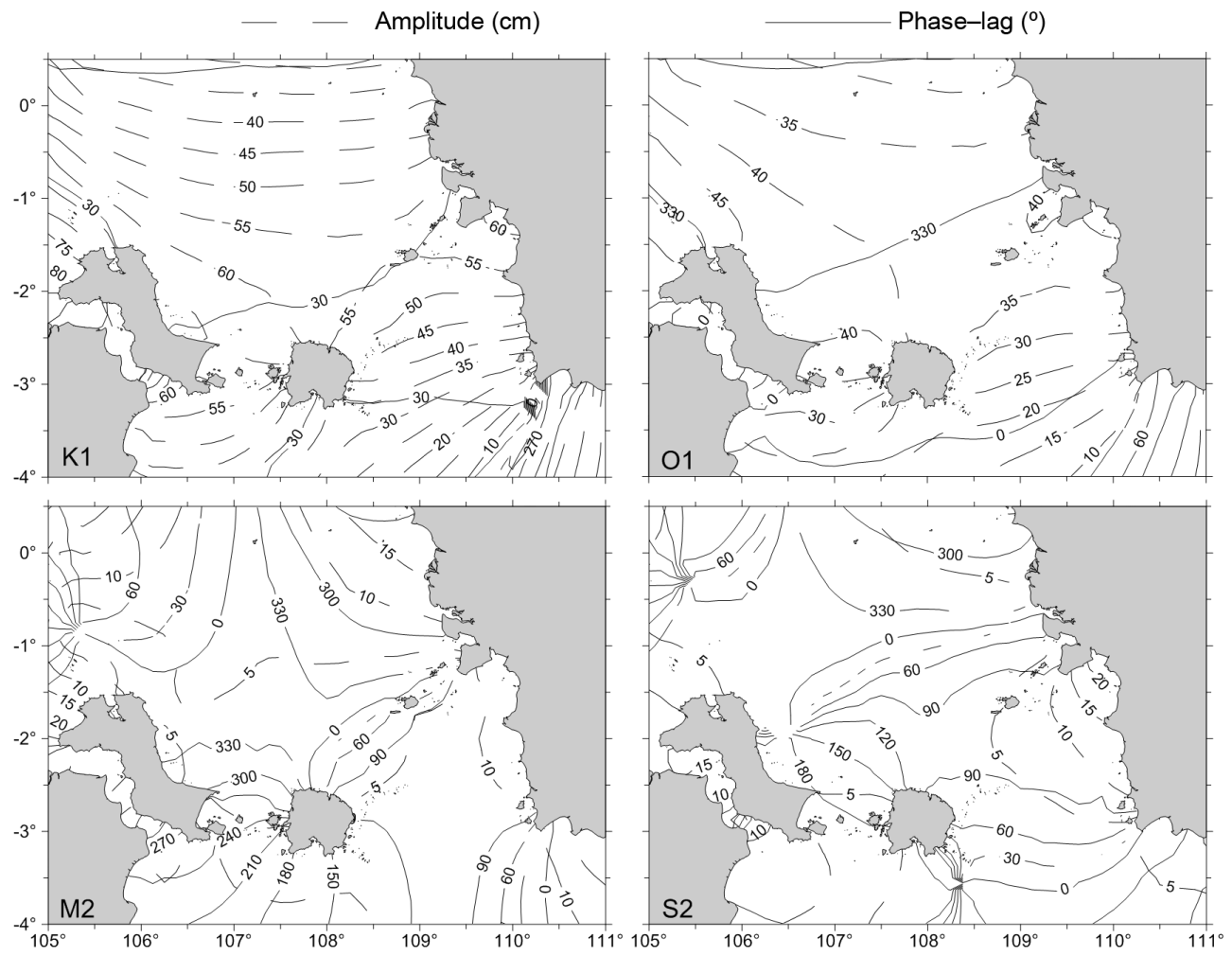

Figure A1. Co-tidal charts for $K_{1}, O_{1}, M_{2}$ and $S_{2}$ based on DTU10. 
Table A1. Comparison between four tidal models and observations.

\begin{tabular}{|c|c|c|c|c|c|c|c|c|c|c|c|c|c|}
\hline \multirow[t]{2}{*}{ Station } & \multirow[t]{2}{*}{ Source } & \multicolumn{3}{|c|}{$K_{1}$} & \multicolumn{3}{|c|}{$O_{1}$} & \multicolumn{3}{|c|}{$M_{2}$} & \multicolumn{3}{|c|}{$S_{2}$} \\
\hline & & $\begin{array}{r}H \\
(\mathrm{~cm})\end{array}$ & $\begin{array}{r}G \\
(\operatorname{deg})\end{array}$ & $\begin{array}{r}\Delta \\
(\mathrm{cm})\end{array}$ & $\begin{array}{r}H \\
(\mathrm{~cm})\end{array}$ & $\begin{array}{r}G \\
(\operatorname{deg})\end{array}$ & $\begin{array}{r}\Delta \\
(\mathrm{cm})\end{array}$ & $\begin{array}{r}H \\
(\mathrm{~cm})\end{array}$ & $\begin{array}{r}G \\
(\operatorname{deg})\end{array}$ & $\begin{array}{r}\Delta \\
(\mathrm{cm})\end{array}$ & $\begin{array}{r}H \\
(\mathrm{~cm})\end{array}$ & $\begin{array}{r}G \\
(\operatorname{deg})\end{array}$ & $\begin{array}{r}\Delta \\
(\mathrm{cm})\end{array}$ \\
\hline \multirow[t]{5}{*}{ A1 } & TPX07.2 & 66.7 & 23.0 & 10.8 & 45.2 & 323.9 & 4.9 & 5.4 & 18.0 & 3.3 & 1.7 & 123.9 & 1.7 \\
\hline & GOT00.2 & 61.5 & 26.5 & 4.4 & 42.0 & 325.3 & 2.8 & 6.4 & 357.5 & 2.9 & 3.0 & 93.6 & 0.7 \\
\hline & NAO.99b & 56.6 & 25.5 & 5.2 & 41.5 & 325.6 & 2.7 & 4.4 & 339.1 & 0.6 & 0.9 & 168.1 & 2.7 \\
\hline & DTU10 & 59.0 & 26.8 & 3.3 & 41.4 & 328.6 & 1.1 & 4.8 & 346.4 & 1.1 & 0.6 & 53.4 & 2.1 \\
\hline & Observation & 59.1 & 30.0 & & 42.4 & 329.1 & & 3.8 & 341.3 & & 2.6 & 82.3 & \\
\hline \multirow[t]{5}{*}{$\mathrm{A} 2$} & TPXO7.2 & 51.0 & 28.1 & 1.0 & 38.3 & 325.2 & 1.4 & 7.6 & 314.3 & 3.3 & 2.3 & 8.8 & 2.3 \\
\hline & GOT00.2 & 53.4 & 24.3 & 3.6 & 37.8 & 323.8 & 2.0 & 5.7 & 325.6 & 1.3 & 0.5 & 135.3 & 2.6 \\
\hline & NAO.99b & 50.8 & 22.8 & 3.7 & 37.4 & 322.2 & 3.0 & 7.3 & 305.3 & 3.4 & 0.2 & 216.1 & 2.9 \\
\hline & DTU10 & 52.6 & 24.5 & 2.9 & 38.4 & 327.2 & 1.0 & 5.4 & 318.4 & 1.1 & 1.6 & 40.2 & 1.4 \\
\hline & Observation & 50.8 & 27.0 & & 37.4 & 326.8 & & 4.4 & 322.9 & & 2.7 & 62.2 & \\
\hline \multirow[t]{5}{*}{ B1 } & TPXO7.2 & 64.6 & 43.8 & 12.4 & 40.3 & 348.0 & 2.4 & 1.8 & 235.7 & 2.5 & 3.6 & 159.1 & 1.7 \\
\hline & GOT00.2 & 61.5 & 30.5 & 3.5 & 36.6 & 337.5 & 5.6 & 1.0 & 285.1 & 3.7 & 4.8 & 156.0 & 0.6 \\
\hline & NAO.99b & 61.8 & 30.8 & 3.4 & 40.3 & 337.5 & 5.1 & 4.0 & 231.6 & 0.5 & 7.9 & 190.4 & 4.3 \\
\hline & DTU10 & 59.8 & 33.4 & 0.2 & 37.4 & 343.1 & 2.4 & 4.2 & 254.6 & 1.3 & 6.1 & 178.8 & 2.0 \\
\hline & Observation & 59.6 & 33.3 & & 39.6 & 344.7 & & 4.3 & 236.4 & & 5.3 & 160.0 & \\
\hline \multirow[t]{5}{*}{ B2 } & TPX07.2 & 55.3 & 34.2 & 10.7 & 38.1 & 338.0 & 10.9 & 2.8 & 13.2 & 3.8 & 3.5 & 97.6 & 2.9 \\
\hline & GOT00.2 & 54.4 & 27.8 & 16.6 & 35.3 & 335.3 & 12.2 & 2.6 & 93.1 & 1.2 & 5.4 & 146.5 & 2.2 \\
\hline & NAO.99b & 52.5 & 30.3 & 14.2 & 35.9 & 337.1 & 11.1 & 4.2 & 9.7 & 5.1 & 2.7 & 19.5 & 6.8 \\
\hline & DTU10 & 55.0 & 31.0 & 13.7 & 37.9 & 339.5 & 9.9 & 2.2 & 76.9 & 1.4 & 4.0 & 94.1 & 2.9 \\
\hline & Observation & 54.4 & 45.4 & & 36.5 & 354.7 & & 1.9 & 117.5 & & 5.6 & 123.8 & \\
\hline \multirow[t]{5}{*}{ B3 } & TPXO7.2 & 51.8 & 34.6 & 5.6 & 36.6 & 337.8 & 4.1 & 2.2 & 3.3 & 2.4 & 3.2 & 85.8 & 5.6 \\
\hline & GOT00.2 & 54.3 & 27.4 & 9.0 & 35.3 & 335.3 & 5.3 & 2.0 & 69.3 & 0.2 & 5.2 & 146.7 & 6.7 \\
\hline & NAO.99b & 53.7 & 30.1 & 6.9 & 36.8 & 335.3 & 5.6 & 6.6 & 353.1 & 6.4 & 4.5 & 8.0 & 9.7 \\
\hline & DTU10 & 54.6 & 30.1 & 6.5 & 37.9 & 338.4 & 4.4 & 2.3 & 63.5 & 0.2 & 4.5 & 97.1 & 4.2 \\
\hline & Observation & 57.2 & 36.2 & & 35.2 & 343.9 & & 2.2 & 68.5 & & 8.7 & 96.5 & \\
\hline \multirow[t]{4}{*}{ Average } & TPX07.2 & & & 8.10 & & & 4.74 & & & 3.06 & & & 2.84 \\
\hline & GOT00.2 & & & 7.42 & & & 5.58 & & & 1.86 & & & 2.56 \\
\hline & NAO.99b & & & 6.68 & & & 5.50 & & & 3.20 & & & 5.28 \\
\hline & DTU10 & & & 5.32 & & & 3.76 & & & 1.02 & & & 2.52 \\
\hline
\end{tabular}

$\Delta=\left[\left(H_{m} \cos G_{m}-H_{o} \cos G_{o}\right)^{2}+\left(H_{m} \sin G_{m}-H_{o} \sin G_{o}\right)^{2}\right]^{1 / 2}$ is the vector difference, with subscripts $m$ and $o$ representing model and observation, respectively. 


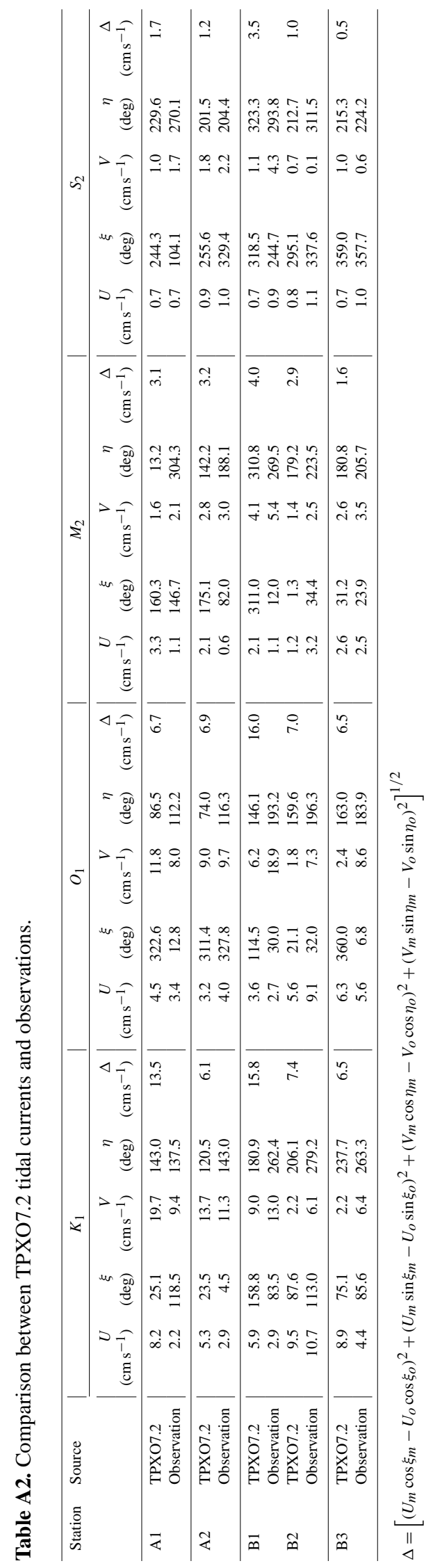


Appendix B: Relationship between the rotation of tidal elevation gradient and the tidal regime

The tidal regime for a specific constituent is conventionally illustrated with a diagram, called the co-tidal chart, showing its co-amplitude contours and co-phase contours. The tidal elevation of the constituent can be written as

$\zeta=H \cos (\omega t-G)$

where $H$ and $G$ are its amplitude and phase lag, respectively, and $\omega$ the angular speed. The equivalent complex form of Eq. (B1) is

$\zeta=\frac{1}{2} H\left(e^{i(\omega t-G)}+e^{-i(\omega t-G)}\right)$.

The $x$ and $y$ components of the tidal elevation gradient are

$$
\begin{aligned}
a \equiv & \frac{\partial \zeta}{\partial x}=\frac{1}{2}\left[\left(\frac{\partial H}{\partial x}-i \frac{H \partial G}{\partial x}\right) e^{i(\omega t-G)}\right. \\
& \left.+\left(\frac{\partial H}{\partial x}+i \frac{H \partial G}{\partial x}\right) e^{-i(\omega t-G)}\right] \\
b & \equiv \frac{\partial \zeta}{\partial y}=\frac{1}{2}\left[\left(\frac{\partial H}{\partial y}-i \frac{H \partial G}{\partial y}\right) e^{i(\omega t-G)}\right. \\
& \left.+\left(\frac{\partial H}{\partial y}+i \frac{H \partial G}{\partial y}\right) e^{-i(\omega t-G)}\right],
\end{aligned}
$$

respectively. The gradient vector on the complex plane is thus equal to

$$
S=a+i b=\frac{1}{2}\left(A e^{i(\omega t-G+\alpha)}+B e^{-i(\omega t-G-\beta)}\right),
$$

where

$$
\begin{aligned}
A & =\left\{\left[\left(\frac{\partial H}{\partial x}\right)^{2}+\left(\frac{\partial H}{\partial y}\right)^{2}\right]+\left[\left(\frac{H \partial G}{\partial x}\right)^{2}+\left(\frac{H \partial G}{\partial y}\right)^{2}\right]\right. \\
& \left.+2\left(\frac{\partial H}{\partial x} \frac{H \partial G}{\partial y}-\frac{\partial H}{\partial y} \frac{H \partial G}{\partial x}\right)\right\}^{1 / 2} \\
B & =\left\{\left[\left(\frac{\partial H}{\partial x}\right)^{2}+\left(\frac{\partial H}{\partial y}\right)^{2}\right]+\left[\left(\frac{H \partial G}{\partial x}\right)^{2}+\left(\frac{H \partial G}{\partial y}\right)^{2}\right]\right. \\
& \left.-2\left(\frac{\partial H}{\partial x} \frac{H \partial G}{\partial y}-\frac{\partial H}{\partial y} \frac{H \partial G}{\partial x}\right)\right\}^{1 / 2} \\
\alpha & =\arctan \left[\left(\frac{\partial H}{\partial y}-\frac{H \partial G}{\partial x}\right) /\left(\frac{\partial H}{\partial x}+\frac{H \partial G}{\partial y}\right)\right] \\
\beta & =\arctan \left[\left(\frac{\partial H}{\partial y}+\frac{H \partial G}{\partial x}\right) /\left(\frac{\partial H}{\partial x}-\frac{H \partial G}{\partial y}\right)\right] .
\end{aligned}
$$

The first term on the right-hand side of Eq. (B5) represents a vector rotating counterclockwise with its tip along a circle of radius $A$, and the second term represents a vector rotating clockwise with its tip along a circle of radius $B$. Their sum divided by 2 is the tidal elevation gradient vector $\boldsymbol{S}$ whose tip traces an ellipse, called the tidal elevation gradient ellipse. The parameters of the ellipse can be readily derived from $A$, $B, \alpha$, and $\beta$ (Godin, 1972, paragraph 2.6.1; Fang, 1984):

semi-major axis length $=A+B$

ellipticity $=(A-B) /(A+B)$

phase lag of maximum gradient $=G+\frac{1}{2}(\beta-\alpha)$

direction of maximum gradient $=\frac{1}{2}(\alpha+\beta)$

From Eq. (B5) we can see that the vector $S$ rotates counterclockwise (clockwise) when $A>B(A<B)$. From Eqs. (B6) and (B7) the magnitudes of $A$ and $B$ can be further written as

$$
\begin{aligned}
\psi A & =\left(|\operatorname{grad} H|^{2}\right. \\
& \left.+|H \operatorname{grad} G|^{2}+2|\operatorname{grad} H||H \operatorname{grad} G| \sin \right)^{1 / 2} \\
\psi B & =\left(|\operatorname{grad} H|^{2}\right. \\
& \left.+|H \operatorname{grad} G|^{2}-2|\operatorname{grad} H||H \operatorname{grad} G| \sin \right)^{1 / 2},
\end{aligned}
$$

where $\psi$ is the angle from the vector grad $H$ to the vector $\operatorname{grad} G$. Therefore, the tidal elevation gradient ellipse becomes a counterclockwise (clockwise) rotating circle if $\psi=90^{\circ}\left(-90^{\circ}\right)$; it reduces to a straight line if $\psi=0^{\circ}$ or $180^{\circ}$; it rotates counterclockwise (clockwise) if $\psi$ lies between 0 and $180^{\circ}\left(0\right.$ and $\left.-180^{\circ}\right)$. The directions of the vectors grad $H$ and $\operatorname{grad} G$ and the angle $\psi$ can be readily obtained from the co-amplitude and co-phase contours in the co-tidal chart. 
Acknowledgements. This study was supported by the International Cooperation Program of China (Grant no. 2010DFB23580), the National Basic Research Program of China (973 Program) (Grant no. 2011CB403502), the NSFC-Shandong Joint Fund for Marine Science Research Centers (Grant no. U1406404), the National High Technology Research and Development Program (863 Program) (Grant no. 2013AA09A506), the National Natural Science Foundation of China (Grant nos. 41476025 and 41306031), the State Oceanic Administration of China (Grant no. 2200207), the Basic Research Operating Funds of the First Institute of Oceanography, State Oceanic Administration (Grant nos. 2014G26 and 2013G35), the National Science Foundation of the United States (Grant no. OCE-07-25935), and the Office of Naval Research of the United States (Grant no. N00014-08-1-0618).

Edited by: N. Wells

\section{References}

Beardsley, R. C., Duda, T. F., Lynch, J. F., Irish, J. D., Ramp, S. R., Chiu, C. S., Tang, T. Y., Yang, Y. J., and Fang, G. H.: Barotropic tide in the northeast South China Sea, IEEE J. Ocean. Eng., 29, 1075-1086, 2004.

Cheng, Y. C. and Andersen, O. B.: Multimission empirical ocean tide modeling for shallow waters and polar seas, J. Geophys. Res., 116, C11001, doi:10.1029/2011JC007172, 2011.

Cressman, G. P.: An operational objective analysis system, Mon. Weather Rev., 87, 367-374, 1959.

Egbert, G. D. and Erofeeva, S. Y.: Efficient inverse modeling of barotropic ocean tides, J. Atmos. Ocean. Tech., 19, 183-204, 2002

Fang, G. H.: Basic characteristics of the vertical structure of tidal currents - A comparison of theory and observations, Marine Sciences, 8, 1-11, 1984 (in Chinese with English abstract).

Fang, G. H. and Ichiye, T.: On the vertical structure of tidal currents in a homogeneous sea, Geophys. J. Roy. Astr. S., 73, 65-82, 1983.

Fang, G. H., Kwok, Y. K., Yu, K. J., and Zhu, Y. H.: Numerical simulation of principal tidal constituents in the South China Sea, Gulf of Tonkin and Gulf of Thailand, Cont. Shelf Res., 19, 845869, 1999.

Fang, G. H., Susanto, R. D., Wirasantosa, S., Qiao, F. L., Supangat, A., Fan, B., Wei, Z. X., Sulistiyo, B., and Li, S. J.: Volume, heat, and freshwater transports from the South China Sea to Indonesian seas in the boreal winter of 2007-2008, J. Geophys. Res., 115, C12020, doi:10.1029/2010JC006225, 2010.

Foreman, M. G. G.: Manual for tidal heights analysis and prediction. Pacific Marine Science Report 77-10, Institute of Ocean Science, Victoria, B. C., 101 pp., 1977.
Gao, X. M, Wei, Z. X., Lv, X. Q., Wang, Y. G., and Fang G. H.: Numerical study of tidal dynamics in the South China Sea with adjoint method, Ocean Modell., 92, 101-114, doi:10.1016/j.ocemod.2015.05.010, 2015.

Godin, G.: The Analysis of Tides, University of Toronto Press, Toronto, 264 pp., 1972.

Hatayama, T., Awaji, T., and Akitomo, K.: Tidal currents in the Indonesian seas and their effect on transport and mixing, J. Geophys. Res., 101, 12353-12373, 1996.

Matsumoto, K., Takanezawa, T., and Ooe, M.: Ocean tide models developed by assimilating TOPEX/POSEIDON altimeter data into hydrodynamical model: A global model and a regional model around Japan, J. Oceanogr., 56, 567-581, 2000.

Mazzega, P. and Berge, M.: Ocean tides in the Asian semienclosed seas from TOPEX/POSEIDON, J. Geophys. Res., 99, 2486724881, 1994.

Pawlowicz, R., Beardsley, B., and Lentz, S.: Classical tidal harmonic analysis including error estimates in MATLAB using T_TIDE, Comput. Geosci., 28, 929-937, 2002.

Proudman, J. and Doodson, A. T.: The principal constituent of the tides of the North Sea, Philos. T. R. Soc. Lond., A224, 185-219, 1924.

Pugh, D. T.: Tides, Surges, and Mean Sea Level, John Wiley \& Sons Ltd., New York, United States, 472 pp., 1987.

Ray, R. D.: A global ocean tide model from TOPEX/POSEIDON altimetry: GOT99.2. NASA/TM-1999-209478, Goddard Space Flight Centre, Greenbelt, MD, USA, 1999.

Ray, R. D., Egbert, G. D., and Erofeeva, S. Y.: A brief overview of tides in the Indonesian seas, Oceanography, 18, 74-79, 2005.

Robertson, R. and Ffield, A.: $M_{2}$ baroclinic tides in the Indonesian seas, Oceanography, 18, 62-73, 2005.

Robertson, R. and Ffield, A.: Baroclinic tides in the Indonesian seas: Tidal fields and comparisons to observations, J. Geophys. Res., 113, C07031, doi:10.1029/2007JC004677, 2008.

Susanto, R. D., Wei, Z. X., Adi, R. T., Fan, B., Li, S. J., and Fang, G. H.: Observations of the Karimata Strait througflow from December 2007 to November 2008, Acta Oceanol. Sin., 32, 1-6, doi:10.1007/s13131-013-0307-3, 2013.

Teng, F., Fang, G. H., Wang, X. Y., Wei, Z. X., and Wang, Y. G.: Numerical simulation of principal tidal constituents in the Indonesian adjacent seas, Advances in Marine Science, 31, 166-179, 2013 (in Chinese with English abstract).

Wang, J. and Fang, G. H.: An analysis of incomplete hourly tidal records. Acta Oceanol. Sin., 3, 193-210, 1981 (in Chinese with English abstract).

Wyrtki, K.: Physical oceanography of the Southeast Asian waters, Scientific Results of Marine Investigations of the South China Sea and the Gulf of Thailand 1959-1961, NAGA Rep. 2, Scripps Inst. of Oceanogr., La Jolla, California, 195 pp., 1961. 